\title{
Article \\ Hyponatremia in Children and Adults with Prader-Willi Syndrome: A Survey Involving Seven Countries
}

\author{
Muriel Coupaye ${ }^{1,2,3, * \mathbb{C}}$, Karlijn Pellikaan $4,5,6,7 \oplus$, Anthony P. Goldstone $2,8(\mathbb{D}$, Antonino Crinò 2,9®,

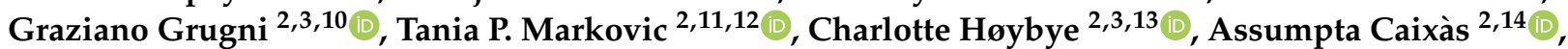 \\ Helena Mosbah 1,3(D), Laura C. G. De Graaff ${ }^{2,3,4,5,6,7}$, Maithé Tauber ${ }^{3,15}$ and Christine Poitou 1,2,3,16
}

1 Assistance Publique-Hôpitaux de Paris, Rare Diseases Center of Reference 'Prader-Willi Syndrome and Obesity with Eating Disorders' (PRADORT), Nutrition Department, Pitié-Salpêtrière Hospital, F-75013 Paris, France; helena.mosbah@aphp.fr (H.M.); christine.poitou-bernert@aphp.fr (C.P.)

2 International Network for Research, Management \& Education on Adults with Prader-Willi Syndrome; tony.goldstone@imperial.ac.uk (A.P.G.); a.crino@tiscali.it (A.C.); g.grugni@auxologico.it (G.G.); tania.markovic@sydney.edu.au (T.P.M.); charlotte.hoybye@sll.se (C.H.); acaixas@gmail.com (A.C.); 1.degraaff@erasmusmc.nl (L.C.G.D.G.)

3 European Reference Network on Rare Endocrine Conditions; 1.degraaff@erasmusmc.nl (L.C.G.D.G.); tauber.mt@chu-toulouse.fr (M.T.)

4 Department of Internal Medicine, Division of Endocrinology, Erasmus Medical Center, University Medical Centre Rotterdam, 3015 GD Rotterdam, The Netherlands; k.pellikaan@erasmusmc.nl (K.P.);

1.degraaff@erasmusmc.nl (L.C.G.D.G.)

5 Department of Internal Medicine, Division of Endocrinology, Center for Adults with Rare Genetic Syndromes, Erasmus Medical Center, University Medical Center Rotterdam, 3015 GD Rotterdam, The Netherlands; k.pellikaan@erasmusmc.nl (K.P.); 1.degraaff@erasmusmc.nl (L.C.G.D.G.)

check for updates

Citation: Coupaye, M.; Pellikaan, K.; Goldstone, A.P.; Crinò, A.; Grugni, G.; Markovic, T.P.; Høybye, C.; Caixàs, A.; Mosbah, H.; De Graaff, L.C.G.; et al. Hyponatremia in Children and Adults with Prader-Willi Syndrome: A Survey Involving Seven Countries. J. Clin. Med. 2021, 10, 3555. https:// doi.org/10.3390/jcm10163555

Academic Editor: Claire J. Stocker

Received: 17 July 2021

Accepted: 9 August 2021

Published: 12 August 2021

Publisher's Note: MDPI stays neutral with regard to jurisdictional claims in published maps and institutional affiliations.

Copyright: (c) 2021 by the authors. Licensee MDPI, Basel, Switzerland. This article is an open access article distributed under the terms and conditions of the Creative Commons Attribution (CC BY) license (https:// creativecommons.org/licenses/by/ $4.0 /)$.
6 Dutch Center of Reference for Prader-Willi Syndrome, 3015 GD Rotterdam, The Netherlands; k.pellikaan@erasmusmc.nl (K.P.); l.degraaff@erasmusmc.nl (L.C.G.D.G.)

7 Academic Centre for Growth Disorders, Erasmus Medical Center, University Medical Centre Rotterdam, 3015 GD Rotterdam, The Netherlands; k.pellikaan@erasmusmc.nl (K.P.); 1.degraaff@erasmusmc.nl (L.C.G.D.G.)

8 PsychoNeuroEndocrinology Research Group, Centre for Neuropsychopharmacology, Division of Psychiatry, and Computational, Cognitive and Clinical Neuroimaging Laboratory, Department of Brain Sciences, Faculty of Medicine, Imperial College London; Department of Endocrinology, Imperial College Healthcare NHS Trust; Hammersmith Hospital, London W12 0NN, UK

9 Reference Center for Prader-Willi Syndrome, Bambino Gesù Hospital, Research Institute, 00050 Palidoro, Italy

10 Divison of Auxology, Istituto Auxologico Italiano, IRCCS, 28824 Piancavallo, Italy

11 Metabolism \& Obesity Services, Royal Prince Alfred Hospital, Camperdown, NSW 2050, Australia

12 Charles Perkins Centre, Faculty of Medicine and Health, University of Sydney, Sydney, NSW 2006, Australia

13 Department of Molecular Medicine and Surgery, and Department of Endocrinology, Karolinska Institute and Karolinska University Hospital, 17176 Stockholm, Sweden

14 Department of Endocrinology and Nutrition, Hospital Universitari Parc Taulí, Institut d'Investigació i Innovació Parc Taulí (I3PT), Universitat Autònoma de Barcelona, 08208 Sabadell, Spain

15 Rare Diseases Center of Reference 'Prader-Willi Syndrome and Obesity with Eating Disorders' (PRADORT), Department of Endocrinology, Bone Diseases, Genetics, and Gynecology, Children's Hospital, Institut Toulousain des Maladies Infectieuses et Inflammatoires (Infinity) INSERM UMR1291—CNRS UMR5051-Université Toulouse III, F-31000 Toulouse, France

16 INSERM, Nutrition and Obesities: Systemic Approaches (NutriOmics), Research Unit, Sorbonne University, F-75013 Paris, France

* Correspondence: muriel.coupaye@aphp.fr; Tel.: +33-(0)-142175771 
these, five recovered completely, but two died. The causes of severe hyponatremia were desmopressin treatment for nocturnal enuresis $(n=2)$, EFI $(n=2)$, adrenal insufficiency $(n=1)$, diuretic treatment $(n=1)$ and unknown $(n=1)$. In conclusion, severe hyponatremia was very rare but potentially fatal in PWS. Desmopressin treatment for nocturnal enuresis should be avoided. Enquiring about EFI and monitoring serum sodium should be included in the routine follow-ups of patients with PWS.

Keywords: Prader-Willi syndrome; hyponatremia; excessive fluid intake; syndrome of inappropriate antidiuretic hormone; desmopressin

\section{Introduction}

Hyponatremia, defined as a serum sodium concentration below $135 \mathrm{mmol} / \mathrm{L}$, is the most common electrolyte disorder encountered in clinical practice and has affected up to $30 \%$ of hospitalized patients across numerous studies throughout the world over the last several decades $[1,2]$. Severe hyponatremia $(<125 \mathrm{mmol} / \mathrm{L})$ can lead to life-threatening neurological symptoms (e.g., confusion, seizures, coma), especially if it occurs rapidly [3]. Several factors that might contribute to hospital-acquired hyponatremia have been identified, including increasing age [1], diuretics, surgery, hypotonic intravenous fluids and several drugs and diseases that promote the release of antidiuretic hormone [4]. Indeed, the syndrome of inappropriate antidiuretic hormone (SIADH) is the most common cause of hyponatremia and occurs when there is persistent secretion of antidiuretic hormone (ADH, also called vasopressin) despite hyponatremia [5,6].

Prader-Willi syndrome (PWS) is a rare genetic neuro-endocrine developmental disorder and the most common form of syndromic obesity with an incidence of approximately 1 in 21,000 newborns [7]. This genetic syndrome is caused by a loss of the expression of paternally inherited imprinted alleles on chromosome 15q11-q13 that can occur via three mechanisms. The main genetic mechanism is a paternal deletion in about $60 \%$, followed by maternal uniparental disomy (mUPD) in 36\% and imprinting defects in $4 \%$ of the overall PWS population [8]. Impaired hypothalamic development and function are the causes of many of the phenotypes comprising the developmental trajectory of PWS: from anorexia at birth to excessive weight gain preceding hyperphagia and early-onset severe obesity with combined hormonal deficiencies, behavioral problems and dysautonomia [9]. Among the hormonal deficits, hypogonadism is the most frequent in PWS, with expression in both sexes and at all ages [9] and sex hormone substitution could present a greater risk for hyponatremia in women [10]. In addition, central adrenal insufficiency is rare, about $1 \%$ in adults with PWS [11], but is known to induce hyponatremia.

Severe hyponatremia in patients with PWS was only reported in three studies involving adults [12,13] and an infant [14], despite universal hypothalamic-pituitary axis dysfunction in PWS, as well as an increased risk of water intoxication by excessive fluid intake (EFI), at least in patients with MUPD [12]. In addition, patients with PWS are frequently exposed to psychotropic medications that are known to cause SIADH (i.e., carbamazepine, tricyclic and selective serotonin reuptake inhibitor (SSRI) antidepressants, phenothiazines, haloperidol) [6]. Moreover, some patients may receive desmopressin treatment (synthetic analog of ADH) to manage nocturnal enuresis, which is observed in PWS [15]. Finally, the possibility of SIADH due to dysfunction of the hypothalamic nuclei engaged in ADH production in patients with PWS was suggested in one study [12] but has not been confirmed clinically.

Recently, four French adults with PWS experienced severe hyponatremia, leading to death in one case, prompting a national survey. However, no other case of severe hyponatremia was reported in adults or children. This led to performing a retrospective cohort study in nine reference centers for PWS of the International Network for Research, Management and Education on adults with PWS (INfoRMEd-PWS) to collect all the cases of hyponatremia. The aim of this study was to describe cases of hyponatremia in patients 
with PWS that were followed in seven countries and provide clinical recommendations to prevent severe hyponatremia.

\section{Methods}

\subsection{Study Rationale and Design}

The first part was a case series of four severe hyponatremia patients who were investigated using a descriptive clinical study. Then, we conducted a retrospective cohort study based on medical records of nine reference centers for PWS in seven countries constituting the INfoRMEd-PWS. All patients with genetically confirmed PWS had at least one systematic health screening every year, consisting of a medical interview, a complete physical examination and routine biochemical measurements. In October 2020, each center's investigator reviewed medical data from the last decade of their reference center for PWS to report all cases of patients with hyponatremia $(\mathrm{Na}<135 \mathrm{mmol} / \mathrm{L})$. Then, the investigator completed the characteristics of patients with hyponatremia (demography, comorbidities), the possible causes and the management of hyponatremia.

All participating centers (nine reference centers for PWS in seven countries) obtained approval from ethics committees and patients or caregivers were informed about the retrospective analysis of the data.

\subsection{Statistical Analysis}

Data are expressed as mean $\pm \mathrm{SD}$ (range) or numbers (\%). We used descriptive statistics to report the demographic information and medical data of the patients with hyponatremia.

\section{Results}

The survey was based on 1326 patients (430 children and 896 adults) with PWS that were currently or had been (patients lost to follow-up or deceased) under the care of nine reference centers for PWS in seven countries in Europe and Australia: France (265 children and 315 adults), Italy (135 children and 252 adults), the Netherlands (122 adults), Spain ( 30 children and 50 adults), United Kingdom (46 adults), Sweden (41 adults) and Australia (70 adults).

Among these 1326 patients with PWS, 34 (2.6\%) had at least one episode of mild or moderate hyponatremia $(125 \leq \mathrm{Na}<135 \mathrm{mmol} / \mathrm{L})$, including two children $(0.02 \%)$, and $7(0.5 \%)$ had a severe episode of hyponatremia $(\mathrm{Na}<125 \mathrm{mmol} / \mathrm{L})$, all being adults.

\subsection{Individual Clinical Presentation of the Four Most Recent Cases with Severe Hyponatremia}

We first detailed the four most recent and severe French cases from the reference center of Pitié Salpêtrière hospital in Paris.

The first case was a 41-year-old male with mUPD. His routine treatment comprised $12.5 \mathrm{mg}$ of the antipsychotic medication loxapine at bedtime, glucose-lowering medications (gliclazide, metformin, sitagliptin), antihypertensive medication (irbesartan) and allopurinol. He had nocturnal enuresis for several years, for which a urologist initially prescribed $120 \mu \mathrm{g} /$ day of sublingual desmopressin (Minirin Melt ${ }^{\circledR}$ ), but since this was ineffective, the dose was doubled to $240 \mu \mathrm{g} /$ day. Three days later, the patient developed generalized tonic-clonic seizures and was admitted to the intensive care unit (ICU). His serum sodium on admission was $115 \mathrm{mmol} / \mathrm{L}$. His brain computed tomography (CT) scan was normal. Neither urine electrolyte, urine osmolality analysis, measurement of serum cortisol, nor thyroid function tests were performed, as the etiology of the hyponatremia was considered to be undoubtedly related to the desmopressin. The serum sodium returned to normal on day 3 after fluid restriction and administration of oral $\mathrm{NaCl}$. Desmopressin was stopped and there has been no recurrence of hyponatremia.

The second case was a 27-year-old male with mUPD with a history of EFI for 5 years after beginning psychotropic drug therapy (12.5 mg per day of loxapine and $200 \mathrm{mg}$ per day of topiramate). In December 2019, he had an episode of diarrhea for 3 days and suddenly developed generalized tonic-clonic seizures. On admission to the ICU, his 
serum sodium was $119 \mathrm{mmol} / \mathrm{L}$, urinary osmolality was $169 \mathrm{mOsmol} / \mathrm{kg}$ and urinary sodium was $25 \mathrm{mmol} / \mathrm{L}$. There was no thyroid nor cortisol insufficiency. He recovered in 5 days with fluid restriction and the hyponatremia has not recurred to date with fluid restriction $(1.5 \mathrm{~L} / \mathrm{d})$.

The third case was a 23-year-old female with mUPD. Her only known medication was a growth hormone treatment. She had a history of nocturnal enuresis and was treated with oral desmopressin in childhood (Minirin ${ }^{\circledR}$ tablets). The dose was decreased from 200 to $100 \mu \mathrm{g}$ daily when she was transferred to the adult nutrition department because her serum sodium concentration was $131 \mathrm{mmol} / \mathrm{L}$. Desmopressin was stopped in January 2020 because of persistent mild hyponatremia and a lack of efficacy. In June 2020, she started to have vertigo, then became comatose and was admitted to ICU. Her serum sodium was $115 \mathrm{mmol} / \mathrm{L}$ and her potassium was also low at $3.2 \mathrm{mmol} / \mathrm{L}$ (3.5-5.1). There was no thyroid nor cortisol insufficiency. Her mother reported 3 days of EFI before the coma, but the urinary osmolality was high at $482 \mathrm{mOsmol} / \mathrm{kg}$. Urinary sodium was also elevated at $75 \mathrm{mmol} / \mathrm{L}$, consistent with SIADH. After the serum sodium returned to normal with fluid restriction, she admitted that she secretly took desmopressin tablets. She no longer has access to any desmopressin and there has been no recurrence of hyponatremia to date.

The fourth case was a 31-year-old man with mUPD who was admitted to the psychiatry unit in July 2020 because of psychiatric decompensation, which was related to severe anxiety, in part due to the COVID-19 pandemic. After increasing his psychiatric medication (diazepam, clopixol, loxapine, valproic acid), he displayed confusion, for which he required short-term hospitalization. His serum sodium was $122 \mathrm{mmol} / \mathrm{L}$ at presentation and he recovered within $48 \mathrm{~h}$ with fluid restriction, resulting in the normalization of his serum sodium (139 mmol/L). In November 2020, he slipped and fractured his ankle, for which he had surgery on 11 November 2020. When the cast was removed on 1 December 2020, the scar was noted to be infected and admission for debridement was recommended, but this was delayed and finally scheduled for 21 December 2020. Serum sodium was $135 \mathrm{mmol} / \mathrm{L}$ on 18 December 2020. On the morning of 21 December 2020, he was found unconscious in the bathroom and was transferred to ICU. His serum sodium was $112 \mathrm{mmol} / \mathrm{L}$, potassium $4.0 \mathrm{mmol} / \mathrm{L}$ (3.5-5.1) and urea $2.3 \mathrm{mmol} / \mathrm{L}$ (2.5-7.4). The brain CT scan found a global erasure of cortical furrows without bleeding or signs of ischemia. Despite the correction of hyponatremia, he developed bilateral areactive mydriasis. A second brain $\mathrm{CT}$ scan found an increase in diffuse edema with effacement of the basal cisterns and an absence of vascularization in the arterial and venous phase. He died on 24 December 2020. After questioning his mother, it is very likely that he drank copious amounts of water from the bathroom tap in response to anxiety about the forthcoming surgery, which was postponed twice.

\subsection{Severe Cases of Hyponatremia in PWS}

Table 1 shows the seven cases of severe hyponatremia $(\mathrm{Na}<125 \mathrm{mmol} / \mathrm{L})$ in adults with PWS from three countries (France, the Netherlands and the United Kingdom), including the four French cases described above. The mean age was $37.2 \pm 11.7$ years (23-55), the sex ratio was close to 1 (4 males and 3 females) and mUPD was the predominant genetic diagnosis $(71 \%)$. In two patients, the hyponatremia was due to the desmopressin that was used to control nocturnal enuresis. In four patients, there were several possible contributory factors, and in the remaining patient, there was no apparent cause. All patients with severe hyponatremia were treated in emergency care and then admitted to ICU. Five patients recovered completely but two patients died (one from cerebral edema and one from probable inhalation of gastric content).

\subsection{Mild or Moderate Cases of Hyponatremia in PWS}

Thirty-four cases of moderate or mild hyponatremia were reported from seven countries (Table 2). All patients were asymptomatic (incidental finding), except one who presented with confusion (serum sodium $127 \mathrm{mmol} / \mathrm{L}$ ), the mean age was 36 years, the 
sex ratio was 1 and $32 \%$ had an mUPD genotype. Two Italian patients were aged under 18 years (14.3 and 17.7 years), no other pediatric cases were reported. Obesity was present in $47 \%$, type 2 diabetes mellitus in $35 \%$ and hypertension in $29 \%$ of patients, all being adults. One-third of patients took psychotropic medication that is known to cause SIADH (carbamazepine, SSRI antidepressant), one-quarter had EFI and, in $12 \%$ of cases, the hyponatremia was likely due to hyperglycemia. No cause of hyponatremia was found in $29 \%$, including the two children (neither thyroid nor cortisol insufficiency), but SIADH was not excluded (no urine electrolyte or osmolality measurements in 30 out of 34 patients).

Table 1. Description of severe cases of hyponatremia in adults with Prader-Willi syndrome from three countries, possible causes and evolution.

\begin{tabular}{|c|c|c|c|c|c|c|c|c|}
\hline & Country & $\begin{array}{c}\text { Gender, Age } \\
\text { (years), Genetic } \\
\text { Diagnosis }\end{array}$ & $\begin{array}{l}\text { Clinical } \\
\text { Symptoms }\end{array}$ & $\begin{array}{l}\text { Serum } \\
\text { Sodium } \\
(\mathrm{mmol} / \mathrm{L})\end{array}$ & $\begin{array}{c}\text { Urinary } \\
\text { Osmolarity } \\
\text { (mOsmol/kg) }\end{array}$ & $\begin{array}{l}\text { Urinary } \\
\text { Sodium } \\
(\mathrm{mmol} / \mathrm{L})\end{array}$ & Possible Causes & Evolution \\
\hline Case 1 & France & Male, 41, mUPD & $\begin{array}{l}\text { Coma } \\
\text { (seizures) }\end{array}$ & 115 & - & - & $\begin{array}{c}\text { Desmopressin for } \\
\text { nocturnal enuresis } \\
\left(\text { Minirin Melt }{ }^{\circledR}\right. \\
240 \mu \mathrm{g} / \mathrm{d} \text { for } 3 \text { days) }\end{array}$ & $\begin{array}{l}\text { Recovery; no } \\
\text { recidivism after } \\
\text { stopping } \\
\text { desmopressin intake }\end{array}$ \\
\hline Case 2 & France & Male, 27, mUPD & $\begin{array}{c}\text { Coma } \\
\text { (seizures) }\end{array}$ & 119 & 169 & 25 & $\begin{array}{c}\text { Excessive fluid intake } \\
\text { and diarrhea for } \\
3 \text { days }\end{array}$ & $\begin{array}{l}\text { Recovery; no } \\
\text { recidivism with fluid } \\
\text { restriction } \\
(1.5 \mathrm{~L} / \mathrm{d})\end{array}$ \\
\hline Case 3 & France & Female, 23, mUPD & $\begin{array}{c}\text { Coma } \\
\text { (seizures) }\end{array}$ & 115 & 482 & 75 & $\begin{array}{l}\text { Hidden intake of } \\
\text { desmopressin } \\
\text { (treatment stopped } \\
\text { for several months) }\end{array}$ & $\begin{array}{l}\text { Recovery; no } \\
\text { recidivism }\end{array}$ \\
\hline Case 4 & France & Male, 31, mUPD & Coma & 112 & - & - & $\begin{array}{l}\text { Possible excessive } \\
\text { fluid intake in few } \\
\text { hours during } \\
\text { hospitalization in } \\
\text { orthopedics }\end{array}$ & $\begin{array}{l}\text { Death (cerebral } \\
\text { edema due to severe } \\
\text { hyponatremia) }\end{array}$ \\
\hline Case 5 & $\begin{array}{l}\text { The } \\
\text { Netherlands }\end{array}$ & Male, 55, mUPD & Seizures & 121 & - & - & Unknown & $\begin{array}{c}\text { Death (probably due } \\
\text { to inhalation of } \\
\text { gastric content) }\end{array}$ \\
\hline Case 6 & $\begin{array}{l}\text { The } \\
\text { Netherlands }\end{array}$ & Female, 29, Del & Seizures & Unknown * & - & - & $\begin{array}{l}\text { Treatment with } \\
\text { furosemide and salt } \\
\text { restriction for cardiac } \\
\text { failure }\end{array}$ & $\begin{array}{l}\text { Recovery (stopped } \\
\text { furosemide) }\end{array}$ \\
\hline Case 7 & $\begin{array}{l}\text { United } \\
\text { Kingdom }\end{array}$ & Female, 39, Del & Confusion & 122 & 149 & 37 & $\begin{array}{l}\text { Central adrenal } \\
\text { insufficiency and } \\
\text { possible SIADH due } \\
\text { to sertraline (but no } \\
\text { regression after } \\
\text { stopping sertraline) }\end{array}$ & $\begin{array}{l}\text { Recovery; fluid } \\
\text { restriction necessary } \\
(2 \mathrm{~L} / \mathrm{d}) \text { to maintain } \\
\text { normal serum } \\
\text { sodium }\end{array}$ \\
\hline
\end{tabular}

mUPD: maternal uniparental disomy; Del: deletion; SIADH: syndrome of inappropriate antidiuretic hormone. * Serum sodium was not available for this case but hyponatremia was mentioned in the medical report.

Table 2. Cases of mild or moderate hyponatremia in patients with Prader-Willi syndrome from seven countries.

\begin{tabular}{|c|c|}
\hline \multicolumn{2}{|c|}{ Characteristics of patients with mild or moderate hyponatremia $(n=34)$} \\
\hline Countries & $\begin{array}{c}\text { France: } 1 \text {; Spain: 1; Australia: 3; United Kingdom: 3; Sweden: 4; } \\
\text { The Netherlands: 10; Italy: } 12\end{array}$ \\
\hline $\begin{array}{c}\text { Serum sodium (mmol/L) } \\
\text { Absence of symptoms of hyponatremia (\%) } \\
\text { Age (years) } \\
\text { Gender }(\%) \\
\text { Genetic subtype }(\%) \\
\text { Body mass index }\left(\mathrm{kg} / \mathrm{m}^{2}\right) \\
\text { Obesity }{ }^{*}(\%) \\
\text { Type } 2 \text { diabetes }(\%) \\
\text { Type } 1 \text { diabetes }(\%) \\
\text { Hypertension }(\%)\end{array}$ & $\begin{array}{c}131.4 \pm 2.7(124-134) \\
33(97) \\
35.8 \pm 10.2(14.3-55) \\
\text { Female: } 17 \text { (50); male: } 17(50) \\
32.2 \pm 8.7 \\
16(47) \\
12(35) \\
1(3) \\
10(29)\end{array}$ \\
\hline \multicolumn{2}{|l|}{ Possible causes of hyponatremia (\%) } \\
\hline $\begin{array}{c}\text { Excess fluid intake (EFI) } \\
\text { Desmopressin treatment } \\
\text { Psychotropic treatment } \\
\text {-Carbamazepine } \\
\text {-SSRI antidepressant (Fluoxetine, Citalopram) } \\
\text { Diuretics } \\
\text {-Bumetanide } \\
\text {-Hydrochlorothiazide } \\
\text { Hyperglycemia }\end{array}$ & $\begin{array}{l}8(24) \\
2(6) \\
11(32) \\
6(18) \\
5(15) \\
3(9) \\
1(3) \\
2(6) \\
4(12)\end{array}$ \\
\hline
\end{tabular}


Table 2. Cont.

\begin{tabular}{cc}
\hline \multicolumn{1}{c}{ Characteristics of patients with mild or moderate hyponatremia $(n=34)$} \\
\hline Unknown cause & $10(29)$ \\
\hline Management (\%) & $8(24)$ \\
\hline Fluid restriction & $4(12)$ \\
Reduce or stop treatment causing SIADH & $6(6)$ \\
Change of antihypertensive treatment & $6(18)$ \\
Improve glycemic control & $13(38)$ \\
No specific management &
\end{tabular}

Results are expressed as mean \pm SD (range) for continuous variables and as number (percentage) for categorical variables. mUPD: maternal uniparental disomy. ICD: imprinting center defect. BMI: body mass index SSRI: selective serotonin reuptake inhibitor. SIADH: syndrome of inappropriate antidiuretic hormone. ${ }^{*}$ Obesity was defined as BMI $\geq 30 \mathrm{~kg} / \mathrm{m}^{2}$ in adults and a BMI Z-score $\geq 3$ in children.

There was no specific management in $38 \%$ of these patients. Fluid restriction was introduced in $24 \%$, medication (psychotropics or antihypertensive treatments) was changed in $18 \%$ and improvement of glycemic control was sought in $18 \%$ of patients (Table 2).

\section{Discussion}

We reported the largest cohort of patients with PWS with a history of hyponatremia to identify the possible causes of hyponatremia and interventions to prevent the development of severe hyponatremia. In our study with data from seven countries, severe hyponatremia was rare $(0.5 \%)$, but moderate or mild cases were more frequent, occurring in $2.6 \%$ of patients with PWS. While this prevalence is low, it is relevant in this vulnerable population. The variability of the prevalence of non-severe hyponatremia among countries can probably be explained by the variability of the frequency of routine serum sodium assessment in patients with PWS among countries.

In our cohort, the prevalence of severe hyponatremia was higher in patients with mUPD (5 out of 7 patients), probably due to an increase in EFI and the presence of psychotropic medication that may promote SIADH. Indeed, behavioral problems and psychiatric diagnoses, such as psychosis, are more common in patients with the mUPD genotype [16]. In agreement with our findings, a previous study reported severe hyponatremia in two adults with PWS due to mUPD, in whom the precipitating factors were EFI and treatment with psychotropic medication known to induce SIADH [12]. In another report of severe hyponatremia in an adult with PWS, water intoxication due to desmopressin treatment for nocturnal enuresis was implicated [13]. In our study, apart from the direct effect of desmopressin treatment in two adults, the etiology of the severe hyponatremia in the other adults with PWS was less clear and likely based on several factors, including EFI and treatment with psychotropic medications known to be associated with SIADH.

Similarly, the etiology of mild-moderate hyponatremia in our cohort was often multifactorial. Type 2 diabetes mellitus was almost twice as common in this cohort (35\% of patients) than the rate of 20\% reported in European adults with PWS [17-19]. In 12\% of those with mild-moderate hyponatremia, hyperglycemia was present and these patients may be more prone to glucose-induced hyponatremia than the general population. While we did not find the cause of non-severe hyponatremia in $29 \%$ of patients, whether they displayed SIADH is not known as urine electrolytes and osmolarity were not measured.

These unexplained cases of hyponatremia could suggest a heightened sensitivity of the hypothalamic nuclei to the over-secretion of ADH in PWS. Given the numerous central endocrine abnormalities in this syndrome [9], a dysregulation of hypothalamic nuclei, both spontaneously and by drugs, is probable and could be contributing to the increased prevalence of hyponatremia in PWS. In the postmortem study of Swaab et al., the number of vasopressin neurons in the hypothalamic paraventricular nucleus of the five cases with PWS was not significantly different from 27 controls, whereas the number of oxytocin neurons was lower in the PWS cases compared to the controls [20]. Although the number of vasopressin cells is not apparently increased in PWS, the density of vasopressin immunostaining was not examined and there may still be over-secretion of vasopressin. Al- 
ternatively, increased renal sensitivity to vasopressin in PWS could be another explanation, though this is difficult to confirm in clinical practice.

Finally, EFI, alone or combined with other causes, was the most frequent etiology of hyponatremia in our cohort, where it was present in up to $15 \%$ of adults with PWS in a previous Swedish study [12]. While the majority of infants with PWS drink an unusually small amount, as they age, episodes of consumption of excessive amounts of water can occur and water intoxication was a frequent cause for hospitalization in Dutch adults with PWS in one study [21]. EFI is likely to be exacerbated by psychiatric medications, many of which result in mouth dryness, which is compounded by the sticky saliva of people with PWS [22]. It is thus important that individuals with PWS, their parents and their caregivers are well informed about this health hazard; the PWS Association USA has published a "water intoxication alert" on their website [23]. Fluid intake in individuals with PWS should always be monitored because of the risk of it becoming excessive with the subsequent development of hyponatremia.

The other unambiguous cause of severe or non-severe hyponatremia is desmopressin treatment in adults with nocturnal enuresis. If this treatment is instituted, fluid intake should be restricted for at least one hour before and eight hours after taking the treatment [24]. However, as water intake is difficult to control in most adults with PWS, desmopressin treatment should be avoided in adults with PWS. In cases of enuresis, patients should be comprehensively reviewed to find the exact mechanism(s) of enuresis and an alternative treatment to improve it [25].

Our study has limitations. The first is the retrospective design of the study. The second is the heterogeneity of the cases between countries. The last one is the absence of the comparison of data due to the absence of accurate retrospective data on the group of patients with PWS without a history of hyponatremia.

\section{Conclusions}

Severe hyponatremia is rare in PWS (0.5\%) but is potentially life threatening, with two deaths in our cohort. Even if there are often multiple causes, the prevalence of severe hyponatremia increases in individuals with $\mathrm{mUPD}$, in whom EFI appears to be more common, and is compounded by the use of psychotropic treatments that can induce $\mathrm{SIADH}$, as well as the use of desmopressin treatment. In our opinion, desmopressin should not be used to treat nocturnal enuresis in adults with PWS because EFI is frequent in these patients and not easily prevented. In addition, treatments that are known to promote SIADH should be used carefully in patients with PWS, especially carbamazepine and SSRI antidepressants. Finally, we recommend that serum sodium should be measured regularly in individuals with PWS, especially in those who demonstrate EFI or take psychotropic drugs that may promote SIADH.

Author Contributions: Conceptualization, M.C. and C.P.; methodology, M.C.; writing original draft preparation, M.C.; writing, review and editing, M.C., K.P., A.P.G., A.C. (Antonino Crinò), G.G., T.P.M., C.H., A.C. (Assumpta Caixàs), H.M., L.C.G.D.G., M.T. and C.P.; supervision, C.P. All authors read and agreed to the published version of the manuscript.

Funding: This research received no external funding.

Institutional Review Board Statement: The study was conducted according to the guidelines of the Declaration of Helsinki and approved by the Institutional Review Board or Ethics Committee of all the centers.

Informed Consent Statement: Informed consent was obtained from all subjects or caregivers involved in the study.

Data Availability Statement: The data are not publicly available due to privacy and ethical restrictions. The data that support the findings of this study are available on request from the corresponding author.

Conflicts of Interest: The authors declare no conflict of interest. 


\section{References}

1. Hawkins, R.C. Age and gender as risk factors for hyponatremia and hypernatremia. Clin. Chim. Acta 2003, 337, 169-172. [CrossRef]

2. Upadhyay, A.; Jaber, B.L.; Madias, N.E. Incidence and Prevalence of Hyponatremia. Am. J. Med. 2006, 119, S30-S35. [CrossRef]

3. Spasovski, G.; Vanholder, R.; Allolio, B.; Annane, D.; Ball, S.; Bichet, D.-G.; Decaux, G.; Fenske, W.; Hoorn, E.J.; Ichai, C.; et al. Clinical practice guideline on diagnosis and treatment of hyponatraemia. Nephrol. Dial. Transplant. 2014, 29, i1-i39. [CrossRef]

4. Beukhof, C.M.; Hoorn, E.J.; Lindemans, J.; Zietse, R. Novel risk factors for hospital-acquired hyponatraemia: A matched case-control study. Clin. Endocrinol. 2007, 66, 367-372. [CrossRef]

5. Verbalis, J.G. Euvolemic Hyponatremia Secondary to the Syndrome of Inappropriate Antidiuresis. Front. Horm. Res. 2019, 52, 61-79. [CrossRef]

6. Peri, A.; Pirozzi, N.; Parenti, G.; Festuccia, F.; Menè, P. Hyponatremia and the syndrome of inappropriate secretion of antidiuretic hormone (SIADH). J. Endocrinol. Investig. 2010, 33, 671-682. [CrossRef] [PubMed]

7. Bar, C.; Diene, G.; Molinas, C.; Bieth, E.; Casper, C.; Tauber, M. Early diagnosis and care is achieved but should be improved in infants with Prader-Willi syndrome. Orphanet J. Rare Dis. 2017, 12, 1-6. [CrossRef] [PubMed]

8. Butler, M.G.; Hartin, S.N.; Hossain, W.A.; Manzardo, A.M.; Kimonis, V.; Dykens, E.; Gold, J.A.; Kim, S.-J.; Weisensel, N.; Tamura, R.; et al. Molecular genetic classification in Prader-Willi syndrome: A multisite cohort study. J. Med. Genet. 2019, 56, 149-153. [CrossRef] [PubMed]

9. Tauber, M.; Hoybye, C. Endocrine disorders in Prader-Willi syndrome: A model to understand and treat hypothalamic dysfunction. Lancet Diabetes Endocrinol. 2021, 9, 235-246. [CrossRef]

10. Stachenfeld, N.S.; Taylor, H.S. Sex hormone effects on body fluid and sodium regulation in women with and without exerciseassociated hyponatremia. J. Appl. Physiol. 2009, 107, 864-872. [CrossRef]

11. Rosenberg, A.G.W.; Pellikaan, K.; Poitou, C.; Goldstone, A.; Høybye, C.; Markovic, T.; Grugni, G.; Crinò, A.; Caixàs, A.; Coupaye, M.; et al. Central Adrenal Insufficiency Is Rare in Adults with Prader-Willi Syndrome. J. Clin. Endocrinol. Metab. 2020, 105, e2563-e2571. [CrossRef]

12. Åkefeldt, A. Water intake and risk of hyponatraemia in Prader-Willi syndrome. J. Intellect. Disabil. Res. 2009, 53, 521-528. [CrossRef] [PubMed]

13. Robson, W.L.; Shashi, V.; Nagaraj, S.; Nørgaard, J.P. Water intoxication in a patient with the Prader-Willi syndrome treated with desmopressin for nocturnal enuresis. J. Urol. 1997, 157, 646-647. [CrossRef]

14. Landau, D.; Hirsch, H.J.; Gross-Tsur, V. Case report: Severe asymptomatic hyponatremia in Prader-Willi Syndrome. BMC Pediatr. 2016, 16, 28. [CrossRef]

15. Equit, M.; Piro-Hussong, A.; Niemczyk, J.; Curfs, L.; von Gontard, A. Elimination disorders in persons with Prader-Willi and Fragile-X syndromes. Neurourol. Urodyn. 2013, 32, 986-992. [CrossRef]

16. Aman, L.C.S.; Manning, K.E.; Whittington, J.E.; Holland, A.J. Mechanistic insights into the genetics of affective psychosis from Prader-Willi syndrome. Lancet Psychiatry 2018, 5, 370-378. [CrossRef]

17. Coupaye, M.; Lorenzini, F.; Lloret-Linares, C.; Molinas, C.; Pinto, G.; Diene, G.; Mimoun, E.; Demeer, G.; Labrousse, F.; Jauregi, J.; et al. Growth Hormone Therapy for Children and Adolescents with Prader-Willi Syndrome Is Associated with Improved Body Composition and Metabolic Status in Adulthood. J. Clin. Endocrinol. Metab. 2013, 98, 328-335. [CrossRef] [PubMed]

18. Pellikaan, K.; Rosenberg, A.G.W.; Kattentidt-Mouravieva, A.A.; Kersseboom, R.; Bos-Roubos, A.G.; Veen-Roelofs, J.M.C.; van Wieringen, N.; Hoekstra, F.M.E.; van den Berg, S.A.A.; van der Lely, A.J.; et al. Missed Diagnoses and Health Problems in Adults with Prader-Willi Syndrome: Recommendations for Screening and Treatment. J. Clin. Endocrinol. Metab. 2020, 105, e4671-e4687. [CrossRef] [PubMed]

19. Crinò, A.; Grugni, G. Update on Diabetes Mellitus and Glucose Metabolism Alterations in Prader-Willi Syndrome. Curr. Diabetes Rep. 2020, 20, 1-11. [CrossRef] [PubMed]

20. Swaab, D.F.; Purba, J.S.; Hofman, M.A. Alterations in the hypothalamic paraventricular nucleus and its oxytocin neurons (putative satiety cells) in Prader-Willi syndrome: A study of five cases. J. Clin. Endocrinol. Metab. 1995, 80, 573-579. [CrossRef]

21. Sinnema, M.; Maaskant, M.A.; van Schrojenstein Lantman-de Valk, H.M.J.; Boer, H.; Curfs, L.M.G.; Schrander-Stumpel, C.T.R.M. The use of medical care and the prevalence of serious illness in an adult Prader-Willi syndrome cohort. Eur. J. Med. Genet. 2013, 56, 397-403. [CrossRef] [PubMed]

22. Boccellino, M.; Di Stasio, D.; Serpico, R.; Lucchese, A.; Guida, A.; Settembre, G.; Di Domenico, M.; Rizzo, A. Analysis of saliva samples in patients with Prader-Willi syndrome. J. Biological Regul. Homeost. Agents 2018, 32, 107-111.

23. Prader-Willi Syndrome Association USA. Available online: https://www.pwsausa.org/wp-content/uploads/2021/01/Waterintoxication.pdf (accessed on 17 April 2021).

24. McCarty, T.S.; Shah, A.D. Desmopressin. In StatPearls [Internet]; StatPearls Publishing: Treasure Island, FL, USA, 2021.

25. Katz, E.G.; MacLachlan, L.S. Nocturnal Enuresis in the Adult. Curr. Urol. Rep. 2020, 21, 1-8. [CrossRef] [PubMed] 